\title{
Non-SVO Constructions in English: Some Pragmatic and Functional Considerations
}

\author{
Elena Martínez Caro \\ University of Madrid, Complutense
}

\begin{abstract}
The purpose of this study is to consider those structures in English which do not exhibit a canonical order, that is an SVO constituent order (considered as the basic and dominant order for English) and the principles which can explain their existence in the language. In the first section we identify these non-SVO constructions in English and in the second we look at some of the pragmatic and functional factors underlying these structures, including notions like theme, verb-object bonding, animatedness, accessibility of the linguistic material and others. To conclude, we postulate that any exhaustive study of word order should present not only a functional and pragmatic dimension but also a more formal one, which would include typological and diachronic factors.
\end{abstract}

\section{Introduction}

English is now considered one of the most consistent and rigid SVO languages. ${ }^{1}$ Although Old English was more a synthetic language and relied mainly on inflectional morphology, Modern English has developed into an analytical language in which word order is now the main signal of grammatical relations. In fact, English has advanced farther along the path to analycity than other Germanic languages.

As a compensation for this fixed order and virtual absence of inflectional endings, English exhibits, on the other hand, a remarkable freedom and flexibility in the assignation of semantic roles to grammatical relations so that it permits an unusual degree of discrepancy between the semantic form and surface structure. ${ }^{2}$ Thus a subject NP may, in principle, represent a wide range of participant roles, e.g. agent, patient, instrument, beneficiary, experiencer, etc.

Despite this dominant SVO order, English has also structures in which this is not so. On the one hand, there are grammatical constructions in which one of the main constituents in the clause does not exhibit this canonical order; on the other, there are other 
structures which have an alternative non-SVO order, despite having grammatical counterparts with canonical order, serving a variety of pragmatic functions. If the syntactic structure of a language is studied by a grammar, the latter should also stipulate the other possible orderings in languages and the conditions under which they occur.

The purpose of this study is to consider those structures in English which do not exhibit a canonical order and the reason for their existing in the language. Due to the limited length of this paper, we will mainly look in here at linguistic factors like the functional and pragmatic principles underlying these structures, although our opinion is that more formal considerations (like those related to language typologies and diachronic factors) should also be taken into account in an exhaustive study of the subject.

\section{Non-Canonical Order Constructions in English}

To start with let us consider the main constructions in which English does not exhibit a SVO order. Firstly, there are those constructions in which the grammatical form shows an inversion of one of the main constituents in the clause (usually the subject) and there is no alternative construction in the language. Thus yes/no and Wh-questions have a VS order or, as Dik (155) puts it, a P1 Vf S Vi O ${ }^{3}$ pattern:

(1) a. Have you got any matches left?

b. Is your father at home? ${ }^{4}$

c. Can you play the guitar?

d. What do you want for lunch?

e. Where are you going this summer?

In (1a-c) there is only one element before the subject, which is the finite part of the verb (Vf in Dik's terms); in (1d-e) we have this Vf element plus the interrogative Wh-element which both precede the subject of the sentence. There is, however, a case in which the order is also SVO in questions and that is when the Wh-word itself is the subject of the sentence:

\section{(1) f. Who came to dinner yesterday?}

Other constructions exhibiting inversion are those which include words such as so, as and other terms with a negative meaning such as neither, nor, only, hardly, etc.:

(2) a. He didn't go and neither did I

b. the object prefix is customarily included when the object noun phrase is animate, as is the case in (2.18) (Allan 69, our underlining)

c. So say the rest of us (Quirk et al 95)

d. Hardly had I left before the quarrelling started (Quirk et al 949)

In these cases there is an element which is placed first in the clause and which seems to trigger the verb with it so that inversion occurs and from a normal SVO order a OVS or 
AVS (A standing for adjunct) results (or rather A Vf S Vi, if we use Dik's terms). The reason for this inversion may be the close relationship or bonding between the verb and the object or adjunct, so that when this latter element is placed first, the verb has to follow. This type of inversion also occurs in cases like the following:

(3) a. Here is John

b. There is the postman

c. Also interesting is the fact that he never married

d. Away went the car like a whirlwind (Quirk et al 948)

e. Equally inexplicable was his behaviour towards his son (Quirk et al 948)

f. Under the bridge stood a dilapidated shack (Givón 190)

g. Once upon a time, in a distant land, there lived a king ... (Givón 190)

where there is an adjunct in the first position of the clause. The resulting inverted order is, then, AVS. Although in both (2) and (3) there is a first element which is placed in first position and triggers inversion, the difference is, in our opinion, that in (2) the inversion is more obligatory, possibly because these constructions are remnants of a previous different word order; whereas in (3) the inversion is more optional and particularly (3d-g) are more literary in tone. ${ }^{5}$ Many linguists have referred to this type of inversion in English: Green (594) calls it "emphatic" inversion; Givón refers to it as "existentialpresentative" fronting of locatives; according to Quirk et al, there is a thematic fronting of an adverbial which causes the subject and the object to be reversed.

But, as Quirk et al (949-50) point out, inversion does not take place when the clause includes a personal pronoun as subject:

(4) a. Here he is

b. ${ }^{*}$ Here is he

(5) a. There they are

b. ${ }^{*}$ There are they

Given that we have pronouns in the object position, it seems we should have the accusative forms of the pronouns to set a paralelism with cases like it is him who knows the answer, not me and thus:

(6) a. *Here is him

b. *There is them

But this is obviously agrammatical as the pronouns are not objects themselves but subjects. And in fact in cases of cleft sentences (which will also look at later on) like the following:

(7) It's he/him that is a genious (Quirk et al 952)

the "focal element" (as Quirk et al refer to it), if a pronoun, can take either the subjective or objective case. Thus he and him are alternatives, him being informal. Possibly the 
unique correct form used to be he but the alternative form him arose as that is the logical form for a pronoun which occupies the object position.

Quirk et al also point out that a pronoun as subject following so may restore the normal statement order:

(8) a. So he has

b. So you say

But subject-auxiliary may persist, even with a pronoun subject, when focus is required on the pronoun:

(9) a. You asked me to leave, and so I did ("and I did so, too")

b. My friends enjoyed it, and so did $I$ ("and $I$ did so, too")

There are other cases which can be considered inversion in English. Let us consider, for instance, the existential sentences:

(10) a. There is a man at the door asking for you

b. There were many people at the party

in which there is considered the grammatical subject, although it is semantically empty. The "logical subject," in Halliday's terms (see "Language Structure" 158), is a man in (10a) and many people in (10b) and as the "real subject" goes toward the end of the clause and English has to have its subject position necessarily filled (unlike Spanish, for instance, which is a pro-drop language), the subject position is filled with an empty element, namely there.

Other cases in English which we consider show inversion are cleft sentences. They give both thematic and focal prominence to a particular element of the clause. Most of them begin with the empty pronoun it followed by the verb to be, which in turn is followed by the element on which the focus falls (see Quirk et al 951). This element on which the focus falls we consider the "logical subject," it being the empty element which English needs in the subject position:

(11) a. It was John who wore his best suit to the dance last night

b. It's teaching that he does for a living

c. It's the girl that I was complaining about (sec Quirk et al 951-52)

Other sentences which exhibit inversion are extrapositions:

(12) a. It is obvious that young children should not be left unsupervised for long

b. That young children should not be left unsupervised for long is obvious

(13) a. It is apparent to everyone that Maud is backward

b. That Maud is backward is apparent to everyone 
Thus sentences showing extraposition-(12a) and (13a) in here-are usually preferred rather than their counterpart constructions - (12b) and (13b). For Allan, the former are governed by the principle of heavy/light material (that we will look at more closely later on) by which heavy material goes at the end of the sentence. These cases are distinguished from those sentences with the following pattern:

(14) a. It's a pleasure to teach her

b. She's a pleasure to teach

(15) a. It's impossible to deal with him

b. He is impossible to deal

The (a) cases present the same structure as the extraposition with an empty anticipatory subject in the first place. In (b) there is a fronting of the object or prepositional object of a nominal clause which replaces the anticipatory $i t$.

Other constructions which we need to consider are left dislocations which involve the fronting of an NP from within a clause and its replacement by a pronoun (see Allan 93) and which normally occur in informal speech:

(16) a. My sixth grade teacher, he had a big effect on me

b. Spiders, I've always been afraid of them

c. That kitten, what's it up to now?

d. John, I bumped into him yesterday

These should be distinguished from cases such as:

(17) a. Bright were the stars that night

b. Delicious that trout was

c. His face I'm not fond of and his character I despise

(17a) and (17c) (from Allan 87 and Quirk et al 947, respectively) are of poetic or emotive style. (17c) helps to point a parallelism between two related elements with contrastive meaning. (17b) includes a fronted adjective as in (17a) but the type of sentence is much more common (see Allan 87 for further details).

Moving an element to the end of the clause is also possible in English. Right dislocations is one possibility:

(18) a. It nearly bit me, a viper I just disturbed by the pond

b. Do you know what it does, a carburettor?

c. Do you like them our new neighbours?

d. They do get enthusiastic, some of them (from Allan 97)

Right dislocands are preceded by a denotating pronoun which mark their role in the clause. As in the case of left dislocations, although there is a movement of (usually) the subject or object to the left or the right side of the sentence, the remaining part does not strictly 
change the order of clause elements, since the element is repeated in the form of a pronoun in its normal place.

As we have already seen, extraposition is another type of breaking the canonical order by placing an element into the initial or final position of the clause. The passive construction can be said to be, in a way, a movement to the right of the agent of the action and a movement to the left of the object or entity receiving the effect of the action. Thus notice the alternation:

(19) a. Anne met me at the airport

b. I was met at the airport by Anne

According to Allan (101), there are two major motivations for using a passive. One is to avoid, on the part of the speaker, a change in the topic of conversation, as the active construction normally fronts the agent of the action and this may lead to a change of the subject. The second motivation for using a passive is where the agentive phrase is much heavier than the previous predicate of the clause. Thus in (20):

(20) a. Was there someone there to meet you?

b. I was met by the acting head of the department

c. The acting head of the department

(20b) would be a probable response to (20a) because the agentive phrase is long and "heavy" by comparison with I was met. In ordinary conversation the passive might be avoided altogether replying with the agentive phrase only, like in (20c) (see Allan 101).

To finish with this account of possible inversions in English we will now refer to the direct quotes with verbs of saying in which the order after the statement quoted is very often VS. According to Quirk et al (946) these sentences containing direct speech seem to provide an example of a construction in which thematic fronting of the direct object is exceptionally easy:

(21) a. "I'm hungry" said Mary

b. "Go away!" said one child; "and don't come back!" growled another (Quirk et al 949)

Quirk et al point out the possibility of proposing an alternative analysis, in which the reporting subject and verb (here said) constitute a dependent comment clause rather than the subject and verb of the sentence. This analysis is favoured by the possibility of placing them in the middle of the direct speech, as a parenthesis:
a. "That's a pity," I said
b. "That," I said, "is a pity"

We believe, however, that the most logical analysis is that of considering the whole sentence including a simple verb and subject and a subordinate clause with object function 
that is moved to the left as the other left dislocations constructions do and thus trigger inversion of the verb and subject, except in cases like (22) in which the subject is a personal pronoun (see what we said above of the non-inversion of a pronominal subject and verb with adverbials words like so, there, here, etc.).

\section{Functional Principles Underlying Word Order in English}

Why do we prefer a specific ordering of elements in a language to another? As we have begun to see in the previous chapter, the response to this question cannot merely be that the order of elements is a necessary property of human language determined by physical factors, ie. that the ordering is a matter of temporal necessity (as language occurs in real time). Rather, it is something which is governed by inherent factors of the syntax of the language by which one sentence is considered to be grammatically acceptable or unacceptable in a language. Apart from these more formal factors, there are also semantic, pragmatic and functional principles by which we can account for many cases of noncanonical orderings in English. In fact, the majority of researchers have assumed that word order can be predicted on the basis of certain factors of sentence or discourse structure, although there has been a lot of debate as to what exactly these factors are. Even though we will also consider these more formal factors, we will mainly focus, however, on the functional principles underlying word order in English. We think that word order can only be understood as an interaction of grammatically inherent and functional and pragmatic principles acting on the language, together with the consideration of diachrony. This is too extent, however, for this piece of work and therefore, we will mainly concentrate on one aspect, namely the pragmatic consideration.

Daneš, in the framework of Prague-School linguistics, distinguishes three levels when considering the syntactic structure of an utterance: the level of grammatical structure, that of semantic structure and that of thematic and contextual organisation of the utterance. These three levels coincide with the three major types of information in terms of which attempts have been made to predict word order: syntactic relations, semantic relations and discourse relations, respectively.

Corresponding to the level of semantic structure which Danes identifies concerning syntactic structure in languages, Finegan (99)—as we have already mentioned above-points out the unusual interplay among grammatical relations and semantic roles which English exhibits. Modern English exercises minimal inflectional constraint on subject noun phrases, for instance, which are then free to represent a very wide range of participant roles: agents, patients, instruments, benefactives, experiencers, locatives, temporals and so on. "Dummy" subjects, empty of any semantic content, also occur:

(23) a. The porter (agent) opened the door

b. The door (patient) opened

c. His first record (instrument) expanded his audiences from friends and neighbours to thousands of strangers

d. The youngest jockey (benefactive) took the prize 
e. John (experiencer) heard his father whispering

f. Boston (locative) is cold in winter

g. The next day (temporal) found us on the road to Alice Springs

h. It became clear that the government had jailed him there

This has to do with the notion of "grammatical metaphor" introduced by Halliday (Functional Grammar 321ff). Metaphorical forms are plausible different representations of the same "non-linguistic state of affairs," so that, for instance, instead of Mary saw something wonderful, we may choose to say Mary came upon a wonderful sight, making the verb into a noun (the object in here), or as Halliday puts it, turning the perception (to see) into a "participant" ( $a$ sight). Or else we could say A wonderful sight met Mary's eyes in which the perception is now split up into the subject and the Actor (a sight), a verb (Process: meet) and the object (or Goal, for Halliday: eyes). ${ }^{6}$

Thus we could say that English, instead of allowing more flexibility in terms of the position of its elements, maintains them in the same position and assigns to them different participant roles without, in turn, changing the inflections of the words. See, in this respect, the contrast in English and Spanish between:

(24) a. Claudia has a headache

b. A Claudia le duele la cabeza

In both cases, Claudia is the "recipient" of the sensations or "bearer" of the state, but English and Spanish express this differently. English maintains the position of suject for Claudia and it does not add any inflection to it; in Spanish, on the contrary, the element is in first position but, as it has the mark of the object (the preposition $a$ ), we know that it is not a subject. The inflection then, in this case, permits the flexible movement in Spanish that moves the object to the first position but not in English that, in order to maintain the first position of the recipient, has to change the function of the element in that position from object to subject.?

Concerning the devices that English uses to mark what is more or less relevant in a sentence or text structure, we must distinguish between written and spoken language. In writing, English has available a wide range of syntactic processes to carry out pragmatic functions; these include all the structures that we have seen in our previous section: passivisation, cleft sentences, left and right dislocations, existential constructions, and so on. The spoken language, besides all this, has a further device to signal focus: sentence stress and intonation. Becker and Laff have suggested that one reason for the existence of fronted constructions in English is that "they allow speakers to avoid marked intonations without sacrificing intended emphasis" (Green 582). Consider the following:

(25) a. Outside stood a little angel

b. A little angel stood outside (from Green 582)

While sentences such as (25b) normally contain one intonation peak, sentences like (25a) typically have two-one in the preposed phrase, and one in the postposed phrase. 
Daneš (227), comparing English with Slavonic (especially Czech) points out that, while in the latter the variability of word order is compensated for by a rather uniform location of the intonational contour (CI), ${ }^{8}$ in English the highly fixed word order is compensated for by a great variety of the possible positions of the $\mathrm{CI}$ in the utterance. Thus in general contrastive emphasis may be conveyed by a set of means: word order, a shift of the CI, and by a specific phonological form of the CI. In English, according to Danes, the second and third possibilities are the most common (see Daneš 225ff for further details).

Intonation is capable of providing three coding functions, according to Stockwell (84): a separational function, by rythmic spacing of words into clusters; a focusing function, by attaching pitch prominence to semantically important material, and by destressing anaphoric material; and an identifying function, by assignment of special contours (eg. rising) to special sentence types like questions. Most of these functions, however, are duplicated in the language by other devices such as serial word order, morphological agreement or specially marked constructions (like most we have considered in our previous section). "Languages rarely allow a significant distinction to be symbolised by only one device. They tend to be redundant, to provide ample insurance that what is not understood from one clue will be picked up from another" (Stockwell 84-85).

Let us now look at the more specific discourse-pragmatic considerations underlying the order of the main constituents in English. Two of the linguists who have most studied these considerations are Russell S. Tomlin and Keith Allan. Tomlin postulates three basic functional principles affecting the word order of natural languages universally: (a) the Theme First Principle (TFP), (b) the Principle of Verb-Object Bonding (VOB), and (c) the Animated First Principle (AFP). While the principle of VOB is comparatively new, both the TFP and the AFP have been discussed in the literature.

The Theme First Principle basically states that in sentences or clauses, information that is more "thematic" tends to precede information that is less "thematic." In other words, it states that "theme" information normally precedes "rheme" information. The principle is an attempt to make more precise and explicit the informal idea that "old" information precedes "new" information. The idea of "old" information involves, according to Tomlin, at least two components: "shared information" (SI) or information that the speaker and hearer merely hold in common and "thematic information" (TI) which involves the signalling of information which is most salient to the development of the particular discourse. It is thematic information that is connected with word order in natural language, and also with issues of voice and sentence prosody, whereas shared information is linguistically connected to issues of definiteness, pronominalisation, and the syntax of the reference.

Let us try to give some evidence of this principle making use of some of the noncanonical order constructions which we saw for English. According to the TFP, if an NP represents TI, it will tend to be definite and it will tend to move to the beginning of the sentence. Similarly, indefinite NPs tend not to be TI and they are more likely to move to the end of the sentence. This can account for the indefiniteness of NPs in existential sentences. Thus see our previous example (10) which we reproduce as (26) here:

(26) There is a man at the door asking for you 
This could also account for the definiteness and indefiniteness of NPs in left and right dislocations, respectively. See some of our previous examples rewritten as (27) and (28) here:

(27) Left dislocations:

a. That kitten, what's it up to now?

b. John, I bumped into him yesterday

(28) Right dislocations:

a. It nearly bit me, a viper I just disturbed by the pond

b. Do you know what it does, a carburettor?

Tomlin himself provides further evidence (54-55, 60 and 62$)$ :

(29) a. *A newspaper, John wants to read it (left-dislocation)

b. *An assignment was hard to do (tough-movement)

c. ?An old oak was cut down by the stranger (passivisation)

d. *There's the man in the garage (there insertion)

e. ??He was here to see you last night, a man (right-dislocation)

Tomlin's Principle of Verb-Object Bonding (VOB) states that the object of a transitive verb forms a more cohesive syntactic and semantic whole than does a transitive verb and its subject. We believe that the same can be applied to certain adjuncts with a close relationship with the verb and thus, this principle would help to account for cases like the following (our previous examples (2) and (3)) in which there is a first-position placement of the object or adjunct which is so closely tied to the verb that triggers inversion of the verb and subject:

(30) a. He didn't go and neither did I

b. So say the rest of us

c. There is the postman

d. Away went the car like a whirlwind

e. Under the bridge stood a dilapidated shack ${ }^{9}$

There is another type of evidence given by Tomlin (77ff) which can show the working of this principle in language. According to Tomlin, this can be demonstrated in two ways. Syntactically, we can prove that it is more difficult to insert material between verb and subject, or that it is more difficult to move the object from the verb than the subject from the verb. Semantically we can demonstrate that the object and verb form an immutable whole while the verb and subject do not. For example, as Tomlin observes, a "sentence qualifier" 10 tends not to separate the object from the verb and it usually appears on the side of the verb opposite the object. Thus see in English:

(31) a. John did not cook the fish

b. Did John cook the fish? 
c. John cooked the fish ${ }^{11}$

As with sentence qualifiers, there seems to be a tendency by which sentence adverbials are not permitted to intervene between the verb and the object though they do separate the verb and subject. If such separation constraints of sentence adverbials are not accidental, argues Tomlin, the principle of VOB provides at least for a partial explanation for such constraints:

(32) a. Unfortunately, John cooked the fish

b. John unfortunately cooked the fish

c. * John cooked unfortunately the fish

d. John cooked the fish unfortunately

Similar argumentation can help to explain the placement of modals ${ }^{12}$ in English:

(33) a. John drives the car

b. John may drive the car

The same can be argued for proverbal replacements (see Tomlin 88):

(34) a. John caught a fish and Mary did, too

b. The bird watched the cat and so did the dog

The third basic principle mentioned by Tomlin, The Animated First Principle (AFP), states that in simple basic transitive clauses, the NP which is most animated will precede NPs which are less animated. Tomlin establishes an "Animatedness Hierarchy" for the purpose of accounting for his principle:

(35) The ANimatedness Hierarchy
a. human $>$ other animate $>$ inanimate
b. agent $>$ benefactive/dative $>$ patient
c. more animated $>$ less animated

Some illustrative examples are the following in English (from Tomlin 108):

(36) a. The mailman crushed the beer can

b. My sister brushed the dog

c. The barber shaved my father

d. The dog ate the bone

e. The dog bit the cat

f. The wind turned the weathervane

g. The lightning struck the dog

The other linguist that has referred extensively to the semantic and pragmatic factors underlying constituent ordering recently is Keith Allan. He considers (retaking, in turn, 
some of J. Kathryn Bock's ideas) the distinction between easily accessible language data and less accessible material. The relative accessibility of language data is often expressed, according to Allan (82), in terms of the following hierarchies, where (other things being equal) items to the left of $>$ are more accessible than items to the right of it:

(37) THE LENGTH HIERARCHY: short > long

THE NOMINAL EXPRESSION HIERARCHY: pronouns $>$ names $>$ descriptions

THE GIVEN/NEW HIERARCHY: given > new

THE FAMILIARITY HIERARCHY: more familiar $>$ less familiar

THE DEFINITICITY HIERARCHY: definite NP $>$ indefinite NP

THE PERSONAL HIERARCHY: I/we $>$ you $>$ humans $>$ animates $>$ inanimates $>$ abstracts

THE REFERENTIALITY HIERARCHY: referential > nonreferential

Some of these hierarchies postulated by Allan consider similar aspects of Tomlin's principles and, in particular, the Theme First Principle seems to contain, at least partially, Allan's given/new and definiticity hierarchies and the Animated First Principle closely relates to the personal hierachy. What seems to be new in Allan is that he states that, assuming that the speaker follows the co-operative principle, he will make deliberate efforts to be as communicatively effective as possible. And a means of attaining this on the part of the speaker is by alternating the easily with the less accessible data in the text, the less accessible data being highlighted in some way (e.g. prosodically) which should ease the hearer's comprehension and so support the co-operative principle:

Consequently texts should not contain juxtapositioning of too much new information, nor too many novel expressions, infrequent items, nor adverse content, and not too many abstract expressions or long words. Obviously there will be an effect on the syntax of an utterance if the speaker is to comply with such conditions. (Allan 81)

With these general considerations in mind, let us look at some of the non-SVO constructions in English from the point of view of some of these hierarchies.

The length hierarchy which states that short and "light" information precedes long and "heavier" one may partly account for the following of our previous examples (renumbered here for ease of the argumentation):

(38) a. Equally inexplicable was his behaviour towards his son (SVA clause-type inversion)

b. There is a man at the door asking for you (existential sentence)

c. It is obvious that young children should not be left unsupervised for long (extraposition)

d. It nearly bit me, a viper I just disturbed by the pond (right dislocation)

e. I was met by the acting head of the department (passive) ${ }^{13}$

Allan also talks of heavy NP shift evidencing this (82):

(39) Those men are lucky who maintain the bloom of youth beyond the age of thirty 
He refers to the light-heavy alternation in the following instances:

(40) a. Do you like them, our new neighbours?

b. Do $<>$ you $<>$ like $<>$ them $<>$, $<>$ our new neighbours? LIGHT $<>$ LIGHT $<>$ HEAVY $<>$ LIGHT $<>$ PAUSE $<>$ HEAVY

c. Do $<>$ you $<>$ like $<>$ our new neighbours?

LIGHT $<>$ LIGHT $<>$ HEAVY $<>$ HEAVY

The hearer finds it easier to process two smaller chunks of information than one larger one and the heavy-light alternation also helps in the processing. This is a significant factor, therefore, for the existence of right dislocations in English. As for the given/new hierarchy, its effects are best appreciated in contextualised sentences. Thus consider:

(41) Let me tell you about the people who live in the village. There's old Tom down at the shop; a real old curmudgeon. Villagers are supposed to be friendly and helpful, but he's certainly not that. Then there's Fred who runs the garage; he's OK. Lives with his son Max in the house across the way. A teacher, Max is. Our next door neighbour. . . (from Allan 86)

Allan proposes the following analysis in terms of given/new for the last piece of the text so that the pattern of $A$ teacher, Max is can be accounted for:

$$
\begin{aligned}
& \ldots \text { across the way. A teacher, Max is. Our next door } \\
& \text { NEW<>PAUSE<>NEW }<>\text { GIVEN }<>\text { NEW }
\end{aligned}
$$

neighbour...

If (41) were spoken, there would be a long pause between way and A teacher, but there would normally be no pause between Max is and Our next door neighbour. Thus we get the pattern in (42) which maintains the alternation between new and given alternation and makes processing easier. According to Allan, "pause" and "given" have a similar function in these sequences: "each of its different way supplies a hiatus in the material which requires controlled processing-by both speaker and hearer" (Allan 86).

The new/given alternation is closely related to the definiticity hierarchy as we have seen when commenting on Tomlin's Theme First Principle. Although Tomlin considers the alternation between old and new information a little confusing, what is normally understood as "old" usually overlaps with the given, with what is called "theme" or "topic" 14 and, in turn, with definiteness. And, on the other hand, new information usually overlaps with "rheme" or "comment" and with indefinite terms. Thus let us consider:

(43) There's a child I know who plays the violin extremely well.

\section{NEW}

INDEFINITE

He plays for two hours everyday ...

GIVEN

DEFINITE 
The first element in an utterance is usually given and this normally coincides with the topic and subject of the utterance. But this is not always so: sometimes constructions "violate" this general pattern to create an irregular structure to express contrast, convey emotive connotations, and so on. Thus non-subject NPs that get fronted are not always given and the reason why they get fronted is frequently to establish them as the topic of the utterance. This is one of the main motivations for moving NPs to the left of the clause:

(44) [I graduated from high school as] an average student. My initiative didn't carry me further than average. History I found to be dry. Math courses I was never good at. I enjoyed sciences ... Football was my bag. (Allan 86 , his emphasis)

Some evidence for the personal (45) and definiticity (46) hierarchies is given below:

a. Tarzan fought the anaconda

b. ?The anaconda fought Tarzan

(46) a. Max bumped into a dwarf

b. ?A dwarf bumped into Max

As Allan states, it is notable that languages have various grammatical devices that show the significance of the initial and final positions in the clause but none that medialise a constituent as a means of making it salient. Thus in English, when the speaker wants to make a clause constituent particularly prominent, its position is very frequently changed to the periphery of the sentence, as in the cases of left and right dislocations. The reason for this fact seems to be that the periphery of utterances is naturally more salient than the middle region. However, by general agreement, the first position tends to be more salient than the final one-all other things being equal (Allan 96).

\section{Concluding Remarks}

Although this has not been an exhaustive study on the issue of non-canonical order constructions in English at all, we can, nevertheless, state that, in our opinion, the subject cannot be exclusively considered from a single point of view. Although we have mostly dealt with the issue of the pragmatic factors and functional principles affecting English word order, there is also a need for considering the different non-canonical order syntactic structures in English under a more formal perspective and accounting for the syntactic rules that operate and under which conditions. The formal component must also include an exhaustive study from a typological perspective, comparing English to other natural languages in the world and postulating, when possible, universal typological principles.

The synchronic typological study of word order is closely related, in turn, to diachronic change. As Givón argues, "it is not likely that one can develop a coherent view of typology without, at the same time, elaborating a coherent view of diachronic change" $(237) .{ }^{15}$ 
Therefore, only the interaction of formal and pragmatic principles can fully account, in our opinion, for the distribution and frequency of this linguistic device which is the order of words in language.

\section{Notes}

1. See however McCawley's work "English as a VSO language."

2. See Finegan (99ff) for further study.

3. Vf stands for the finite form of the verb (usually the auxiliary or modal) and Vi for the nonfinite verb (infinitive and present and past participle). P1 is the clause-initial position used for special purposes.

4. Notice that with the verb to be the Cs or complement of the subject (in this case at home) acts as part of the verb occupying the position of the non-finite form of the verb and reinforcing a verb like to be in English with a low content in meaning. This is, in my opinion, the reason why to have is very often reinforced in questions with got as in our example (1a).

5. Note, nevertheless, that if for (3a) we have Here comes the bus, the order is not really optional (*The bus comes here).

6. For a further account of this see Downing (forthcoming).

7. See Lightfoot's (155ff) interesting comments on the history of the verb like in English. Apparently, like had, in Middle English, the same kind of syntactic and semantic structure as verbs of sensations in Spanish (doler, gustar, etc.) nowadays, i.e. with the recipient of the sensation in the first place and with a mark of object, an inflection (object-subject-verb structures). Thus the following sentences occurred alongside: "The king liked the queen" and "Him liked the queen." Lightfoot explains how, as the grammar of Middle English speakers became underlying SVO, these constructions had to be eliminated.

8. Some authors call this the "sentence stress" or the "logical stress" (see Daneš 226).

9. This principle-as Tomlin remarks (101)-may provide some explanation for why some language or group of languages has a VP-constituent as opposed, say, to an SV-constituent.

10. A term used by Lehmann (Tomlin 81) to class together a number of grammatical morphemes that share the property of modifying the primary predication of a sentence. The major qualifiers are negation markers and interrogative markers, but others include markers which are reflexive, desiderative, and potential.

11. The sentence qualifier (the past-tense morpheme) occurs in here between the verb and object, but it could not have done otherwise as it is a suffix.

12. This is due to Steele (see Tomlin 87 for explanation).

13. This does not mean of course that all long subjects (not even the majority of them, we think) can be shifted in English as in, for instance, The tall bearded man who appeared in the Department yesterday was asking for you (we must thank Angela Downing for this example). We are only explaining here why certain shifts take place in the English language, but this does not imply that the reasons for these shifts can always apply.

14. See Daneš (222) in the framework of the Prague School who first elaborated these aspects, for further comments about terms like topic/comment, theme/rheme, old/new, and so on.

15. See also Downing ("Presentative there") for a discussion of the factors motivating the consolidation of there as a presentative and the decline of $i t$ and that in the same function through the Middle English period and, in general, of the regularising of syntactic patterns in English. 


\section{Works Cited}

Allan, Keith. Linguistic Meaning. Vol. 2. London: Routledge and Kegan Paul, 1986. Daneš, František. “Order of Elements and Sentence Intonation." Intonation. Ed. Dwight Bolinger.

Harmondsworth: Penguin, 1972. 217-31.

Dik, Simon. Studies in Functional Grammar. London: Academic, 1980.

Downing, Angela. "The Discourse Function of Presentative There in Existential Structures in Middle English and Present-Day English: A Systemic-Functional Perspective." Occasional Papers in Systemic Linguistics 4 (1990): 103-25.

. "La 'metáfora gramatical' de M. A. K. Halliday y su motivación funcional en el discurso." Revista Española de Lingüistica, forthcoming.

Finegan, Edward "English." The World's Major Languages. Ed. Bernard Comrie. London: Croom Helm, 1987. 77-109.

Givón, Talmy. Syntax: A Functional-Typological Introduction. Vol. 1. Amsterdam: John Benjamins, 1984.

Green, Georgia M. "Some Wherefores of English Inversions." Language 56 (1980): 582-601. Halliday, M. A. K. An Introduction to Functional Grammar. London: Edward Arnold, 1985. ."Language Structure and Language Function." New Horizons in Linguistics. Ed. John Lyons. Penguin, 1970. 140-65.

Lightfoot, David. The Language Lottery: Toward a Biology of Grammars. Cambridge: MIT Press, 1982.

McCawley, James D. "English as a VSO Language." Language 46 (1970): 286-99.

Moreno, Juan Carlos. Fundamentos de sintaxis general. Madrid: Síntesis, 1987.

Quirk, Randolph, et al. A Grammar of Contemporary English. London: Longman, 1972.

Stockwell, Robert P. Foundations of Syntactic Theory. New Jersey: Prentice Hall, 1977.

Tomlin, Russell S. Basic Word Order: Functional Principles. London: Croom Helm, 1986. 